\title{
Nilutamide Regimen
}

National Cancer Institute

\section{Source}

National Cancer Institute. Nilutamide Regimen. NCI Thesaurus. Code C160092.

A hormone therapy regimen consisting of nilutamide that may be used in the treatment of advanced prostate cancer. 